\title{
APRESENTO-LHES YHWH, O D'US DOS HEBREUS
}

\author{
Isabel Arco Verde Santos \\ Doutoranda em Literatura Comparada/UERJ \\ Professora Assistente de Hebraico da UERJ
}

Wellington Couto de Almeida

Mestrando do Programa de Pós-Graduação em Linguística/UFRJ

Viktoria Freires Moura

Graduanda em Letras Português/Literaturas/UERJ

\begin{abstract}
RESUMO: A manifestação de YHWH para Moisés sela um capítulo importante na história dos hebreus e da humanidade. Entender sua aproximação, sua apresentação e sua recepção no evento do Horebe nos ajudam a entender também a mentalidade que orienta a religiosidade judaico-cristã. Dez pragas não encerram a visão grandiosa deste deus que parece descer de sua corte para caminhar na história dos homens. O embate nítido entre as divindades egípcias e o seu Faraó é o cenário onde Deus e o homem parecem caminhar juntos escrevendo sua história.
\end{abstract}

PALAVRAS-CHAVE: YHWH; Moisés; dez pragas; êxodo

\section{PRESENT THEM YHWH: THE D'US OF THE HEBREWS}

\begin{abstract}
The manifestation of YHWH to Moses seals an essential chapter in the history of the Hebrew people and humankind. Understanding his approach, introduction, and reception at the Horeb event also helps us understand the mentality that guides JudeoChristian religiosity. Ten plagues do not end the huge vision of this god who seems to come down from his court to walk in the history of men. The evident clash between the Egyptian deities and their Pharaoh is the scenario where God and man seem to walk together writing history.
\end{abstract}

KEYWORDS: YHWH; Moses; ten plagues; exodus 
A manifestação primeira de Deus a Moisés que configurou seu chamado reflete uma imagem tenebrosa. Nesta teofania, Moisés vê um arbusto que arde em chamas e não se consome. A curiosidade leva-o a aproximar-se do fenômeno, do cenário que o apavora. Deus lhe chama no vislumbre da cena do arbusto em chamas e, à sua aproximação, lhe chama pelo nome.

Esta cena inaugura a religião dos hebreus. Enquanto a atitude de Abraão de sair de seu clã constitui a atitude que norteia a formação do povo hebreu, é com Moisés que se entende o fundamento da religião judaica e do monoteísmo.

A grandeza deste evento causa-lhe temor, a ponto de esconder sua face da divindade $^{1}$. O movimento mosaico inaugura a postura litúrgica daquele que encontra o divino: o vislumbre inicial, a necessidade de chegar perto daquilo que se admira e a única atitude plausível diante deste encontro é cobrir a face. Este gesto revela que Moisés reconhece na divindade o outro que é muito maior que ele mesmo. Tão grande, tão sublime, tão terrível que é preciso cobrir o rosto, esconder-se reconhecendo sua inferioridade.

Há ainda um outro aspecto neste episódio que pode passar despercebido. Mais adiante, quando Moisés e Arão estão na presença de Faraó, eles afirmam que Deus veio ao encontro deles (niqra' 'aleinu) ${ }^{2}$. Essa assertiva revela que o movimento primeiro é de Deus e não do homem. Quando Moisés, fascinado com o espetáculo que se mostra a sua frente, aproxima-se para contemplá-lo, ele responde o convite de YHWH. A manifestação do Horebe é o convite apresentado a Moisés para motivar esta aproximação.

A paixão a que o grandioso e sublime na natureza dão origem, quando essas causas atuam de maneira mais intensa, é o assombro, que consiste no estado de alma no qual todos os seus movimentos são sustados por um certo grau de horror. Nesse caso, o espírito sente-se tão pleno de seu objeto que não pode admitir nenhum outro nem, consequentemente, raciocinar sobre aquele objeto que é alvo de sua atenção. Essa é a origem do poder do sublime, que, longe de resultar de nossos raciocínios, antecede-os e nos arrebata com uma força irresistível. O assombro, como disse, é o efeito do sublime em seu mais alto

\footnotetext{
1 Exxodo 3, 6.

${ }^{2}$ Exxodo 5,3 .
} 
grau; os efeitos secundários são a admiração, a reverência e o respeito. $^{3}$

É como o movimento litúrgico que se repete no encontro cultual. O ser humano é convidado a participar do encontro - simbolicamente representado pelos sinos que tocam nas igrejas ou dos muezins que conclamam nos miranetes das mesquitas. Os sinos ou os muezins não trazem o convite, é bom frisar. Eles lembram os horários que as comunidades acertaram em se reunir. O convite, na verdade, encontra-se na experiência sensível que nos move à contemplação.

Nos encontros cúlticos, entende-se que quem chega, entendeu o convite e aproximase assim para contemplar aquele que se revelou de forma maravilhosa, em momento de adoração. O segundo momento, consequência deste, é o reconhecimento da própria pequenez, que faz com que o ser humano cubra seu rosto, como uma forma de mostrar que é imerecedor de ali estar, concretizado no ato penitencial.

Moisés é chamado pelo nome e, em seguida esconde o rosto e tira suas sandálias, por ordem divina. YHWH só chama Moisés pelo nome, depois que ele se aproxima, como se o acordasse de seu momento de êxtase diante do evento do Horebe. Este chamado, marca um momento pessoal deste encontro no reconhecimento de seu status diante do divino. A ato penitencial é um momento pessoal de exame às próprias falhas, na tentativa de deixar o ser humano no seu lugar, frente a Deus.

Tirar as sandálias é sinal de respeito e humildade. Moisés reconhece o lugar sagrado e reconhece a autoridade que está a sua frente. Câmara Cascudo ${ }^{4}$ lembra que atitude semelhante ocorre com Josué, diante do anjo que se identifica como chefe do exército de YHWH, após o próprio anjo apontar a necessidade de tirar as sandálias. ${ }^{5}$

Mandando Moisés descalçar-se, para dar uma visão assombrosa do lugar sagrado, Jeová empregou indicação corrente e popular no Egito, dando sugestão material e visível para alcançar o invisível e o abstrato. Doutra forma, naquele tempo, Moisés não compreenderia. ${ }^{6}$

Apesar disso, Moisés, não se curva ao desejo de domar a divindade que ora se lhe apresenta e lhe pede o nome. Sutilmente, vencido o primeiro momento de medo, Moisés

\footnotetext{
${ }^{3}$ BURKE, 1993. P. 65.

${ }^{4}$ CASCUDO, Luís da Câmara. Superstição no Brasil. 5. ed. São Paulo: Global, 2002. P. 199

${ }^{5}$ Josué 5,15

${ }^{6}$ (CASCUDO, 2002, p. 461-462)
} 
tenta aquilo que qualquer mortal tentaria: dominar a deidade e isto seria possível se ele se apropriasse de seu nome. A justificativa mosaica para obter esta informação é deveras importante. Como ele se apresentaria à corte de Faraó? Vindo da parte de quem?

A resposta de Deus enquadra Moisés em seu lugar. Ou melhor: deixa Deus no seu lugar. A tradução (segundo a Bíblia de Jerusalém), diz: Eu sou aquele que é. Disse mais: "Assim dirás aos filhos de Israel: EU SOU me enviou até vós."7

No original hebraico, Deus usa o verbo ser no tempo futuro, na primeira pessoa do singular: 'ehyeh. No capítulo, no verso primeiro do livro de êxodo, quando Moisés chega a Faraó para levar a mensagem do Deus de Israel, que se lhe apresentou na sarça, ele mostra que aprendeu a lição e identifica Deus, na forma do tetragrama sagrado, também traduzido como YHWH, que, na verdade é o verbo ser, na terceira pessoa do singular, na forma do futuro. Ele diz para Faraó que "Ele é" o enviou. Percebe-se, então, que o nome sagrado com o qual se apresenta Deus, de fato, não lhe revela.

Deus assume a forma e o nome que Moisés o traduz. YHWH é, na verdade, o resultado daquilo que o ser humano pode chegar a Deus. Não aquilo que ele realmente é. Deus é 'ehyeh - EU SOU - o homem o traduz como YHWH, - ELE É - reconhecendo que não pode chegar nele. Deus é o outro e ponto.

O uso da forma no futuro e não no presente como se apresenta na tradução não deve nos causar dúvidas. O tempo presente como usamos não se apresenta no hebraico bíblico da mesma forma que o concebemos no hebraico moderno. A tradução no presente não compromete seu entendimento, muito pelo contrário.

Esta apresentação representa um novo momento na história de Israel. No verso 3 do capítulo 6 do livro de $\hat{E x o d o, ~ i s t o ~ s e ~ t o r n a ~ e v i d e n t e, ~ q u a n d o ~ D e u s ~ d i z: ~ " A p a r e c i a ~ a ~}$ Abraão, a Isaac e a Jacó como El Shaddai; mas pelo meu nome, Yahweh, não lhes fui conhecido".

Esta percepção de Deus como o outro, nos remete à teologia Barthiana, para o conceito de Totalmente Outro. Embora aparecesse para Moisés de forma sublime, embora o recrutasse para uma missão, embora demonstrasse se preocupar com o povo sofrido e escravizado de Israel, ele continuava sendo o Totalmente Outro.

Todavia, [e a despeito das "desilusões" que os pretensos profetas nos têm causado] permanece [em nós] o anseio de que venha alguém que

\footnotetext{
${ }^{7}$ Verso 14 de Exodo 3.
} 
nos mostre, realmente, o "totalmente outro", em cuja identidade não podemos penetrar. $^{8}$

Aqui, Deus não se apresenta mais na primeira pessoa, mas assume a forma como Moisés o chama. Não mais o "EU sou", mas o "Ele é", como se assumisse o olhar e a possibilidade humana de ver-se. Realmente, o Totalmente Outro.

No verso 6, quando ainda no Horebe, diante da sarça ardente, a tradução diz: "Portanto dirás aos filhos de Israel: Eu sou Yahweh e vos farei sair de debaixo das cargas do Egito." O texto hebraico do qual se traduz "Eu sou Yahweh" é simplesmente 'any YHWH. Não há mais a forma como Deus se apresentou originalmente a Moisés ('eyheh), porque ele assume a necessidade de se achegar a este povo, na forma como ele pode traduzi-lo e vê-lo. Ele sai de seu lugar para ir ao encontro do ser humano, mas não deixa de ser Deus.

O nome Moisés traz consigo uma ligação cultual. A palavra carece de subsídios para indicar uma origem hebraica. Freud, em seu estudo sobre Moisés e a religião monoteísta, trata desse assunto, concluindo por sua origem egípcia. A base do nome seria o radical que significa criança e seu nome seria uma abreviatura sempre associada a uma divindade egípcia, podendo ser Amon-mose, Ptah-mose ou, talvez, Ah-mose, Toth-mose ou Ra-mose ${ }^{9}$. A leitura hebraica de seu nome, significando tirado das águas, segue a fala da filha de Faraó que o teria encontrado no rio, conforme o verso 10 do capítulo 2 do livro de Exodo. ${ }^{10}$

Essa relação do nome Moisés com a narrativa de seu encontro com YHWH valoriza ainda mais o evento. Freud, aliás, analisa a criação do mito Moisés, o herói do povo judeu, nos mesmos moldes de outros mitos da antiguidade. Não é o caso de tratarmos deste ponto aqui, já que fazemos um outro caminho, mas a homenagem possível a deuses egípcios em seu nome aguça este encontro. Moisés bem poderia assumir a forma "Eu sou", mas não o faz, preferindo a forma "Ele é"

O problema é que a aproximação deste Totalmente Outro com a humanidade não pareceu ser satisfatória para o próprio povo. Moisés retorna a Deus e reclama que desde que chegou a Faraó, falando em seu nome (em nome de Deus), o mal sobreveio ao povo. Esta era a reclamação do povo, apresentada no final do capítulo 5 do livro do Exodo. A

\footnotetext{
${ }^{8}$ BART, 2008. P. 697.

${ }^{9}$ Obras completas, 4729.

${ }^{10}$ Verso 10: "quando o menino cresceu, ela o entregou à filha de Faraó, a qual o adotou e lhe pôs o nome de Moisés dizendo: 'Eu o tirei das águas'."
} 
princípio, Moisés somente pediu para que Faraó liberasse o povo escravo, falando em nome de Deus (Ele é). A resposta veio pela mão pesada de Faraó sobre os hebreus, que levou Moisés a interpelar Deus.

É neste contexto que surge a narrativa das dez Pragas. Embora Deus tenha convencido Moisés mais facilmente, talvez porque tivesse uma história ancestral com Ele $^{11}$, sua chegada a Faraó não recebe a recepção esperada. É certo também que Deus não falou pessoalmente com Faraó, como fez a Moisés. Mas, apesar disto, YHWH vai ao encontro de Faráo.

As pragas são a tentativa de chamar a atenção de Faraó, como aconteceu com Moisés ao ver a sarça ardente. A visão do terrível, do extraordinário poderia suscitar em Faraó a mesma atitude de Moisés. Ou não.

Mas não era só o faraó que precisaria ser convencido. O povo também precisava ser convencido. Se a percepção da existência de uma divindade que olhasse a opressão do povo era acalentadora e até sedutora, o agravamento da situação do povo em seu estado servil no Egito, por causa do movimento que Moisés ora fazia por ordem de YHWH, não lhe convencia do poder deste deus.

Desafiado, YHWH, que já se identifica com Israel, promete intervir com mão poderosa (yad chazaqah). As dez pragas aparecem neste contexto como forma de falar sobre a grandiosidade deste Deus. As catástrofes se sucedem como meio de intimidação. O povo egípcio sofreria diretamente as consequências de cada praga. O povo de Israel, porém, pelo que parece indicar no texto do êxodo, não foi atingido pelas pragas, nem precisou precaver-se em nada.

Há teorias científicas que explicam a possibilidade histórica das 10 pragas ${ }^{12}$, que teria ocorrido entre os anos de 1270 a.C. e 1213 a.C., durante o reinado do faraó Ramsés II. Se os egípcios seriam impactados pelas consequências das pragas, o povo de Israel seria impactado por ser poupado destas consequências.

$\mathrm{E}$, ao que parece, não foram pragas escolhidas a esmo, mas cada uma tinha o objetivo de atacar divindades egípcias. Seria um embate entre YHWH e a fé egípcia. Algumas relações são bem claras, como é o caso da $1^{\mathrm{a}}$. praga, que transformou a água em sangue como afronta à entidade Hapi, protetora do Nilo; ou na $2^{a}$. praga, com a infestação de rãs, afrontando Heqet, a entidade cuja imagem a concebia com cabeça de rã; a 5 a praga

\footnotetext{
${ }^{11}$ Verso 6 do capítulo 3: Eu sou o Deus de teus pais, o Deus de Abraão, o Deus de Isaac e o Deus de Jacó."

${ }^{12}$ Teorias de Colin Humphreys e Siro Trevisanato.
} 
que afligia os animais, como afronta a Serápis ou Hator (deuses protetores do gado); a $8^{\text {a }}$. praga que atingia as colheitas por causa da nuvem de gafanhotos, afrontando os deuses relacionados às colheitas, como Xu e Sebeque; a $9^{\mathrm{a}}$. praga trouxe escuridão ao Egito, afrontando divindade egípcia do sol, deus Rá e, por fim, a $10^{\text {a }}$. praga que promoveu a morte dos primogênitos atingindo diretamente a casa de faraó, identificado pelo egípcios como filho de Deus Rá, o deus sol. ${ }^{13}$ Outras associações não parecem tão claras.

Evidente se faz a necessidade de YHWH mostrar seu poder, superando os poderes e possibilidades das entidades egípcias. Mas algumas particularidades que separam a décima praga das demais.

Todas as pragas necessitavam uma resposta somente de Faraó, que seria seu comprometimento com a liberação dos hebreus do Egito. Cada vez que ele se negava a libertar os hebreus, o povo egípcio sofria. E muito! Mas isso não parecia sensibilizar Faraó.

A tradução do texto bíblico incomoda, porque diz que YHWH endurecia o coração de Faraó. O verbo endurecer se apresenta na mesma raiz que se traduz a mão poderosa de YHWH (chazaq). Decerto, as ações de YHWH na direção de seu povo ao contrário de amolecer o coração real, deixavam-no mais forte, mais duro. É como se o orgulho tornasse Faraó mais duro. Ele cedia, para que a praga acabasse, mas depois voltava atrás em sua decisão, porque não se tocava também com a aflição dos egípcios.

Há um contraste claro entre Faraó e YHWH. Enquanto YHWH promove a aproximação com o ser humano e demonstra sua preocupação com seu sofrimento, assumindo a tutela dos hebreus para lhe promover liberdade, Faraó alimenta uma sequência de eventos que são maléficos para seu povo, porque quer afirmar-se um deus.

Nove pragas poderiam ter sido evitadas se Faraó tivesse tomado uma decisão pelo povo, mas não é o que acontece. E é isto que a narrativa bíblica quer mostrar. Nove pragas dependiam simples e unicamente de Faraó e de seu olhar misericordioso para com seu povo. É um contraste evidente. Temos assim, um Deus que se deixa acolher pelos homens e se identifica com eles e um homem que quer se afirmar deus e não se preocupa em afastar-se dos homens.

\footnotetext{
${ }^{13}$ Guia conheça a história : Egito Pág 128/129/130
} 
A décima praga segue, então, uma estratégia diferente das demais. Ela tem um caráter mais amplo e poderia alcançar também os hebreus, tanto que o texto bíblico apresenta a necessidade de se preparar para não sofrer as consequências dela.

Percebe-se também que esta praga é a única que exige uma ação capaz de livrar qualquer um que siga as instruções apresentadas ao povo. Até então, para nenhuma outra praga pode-se evitar as consequências. O único capaz de fazer cessar o mal - além de YHWH - seria Faraó, atendendo ao pedido de libertação do povo hebreu. Para esta última, no entanto, instruções foram dadas capazes de evitar que o mal alcançasse o desfecho premeditado.

Não é só a vida e a morte que estão em jogo. Não se sabe quantas pessoas morreram em consequência das nove pragas anteriores a esta. Esta praga implicava em direitos e herança, já que atingia os primogênitos.

Seguir as instruções protegeria, assim, os primogênitos deste flagelo que atingiria egípcios ou hebreus, da corte de Faraó ou da casa dos escravos e até mesmo de animais era a solução. Ninguém seria poupado, mas bastaria marcar a porta da casa com sangue de cordeiro e não sair de casa na noite fatídica.

Estes cuidados, no entanto, tinham força espiritual mais do que uma eficácia por si mesmos. Marcar as portas com o sangue do cordeiro não salvaria ninguém de algum mal súbito ou enfermidade. Não era de fato um antídoto ou vacina física. Mas, neste sentido, algo, além daquilo que poderia ser óbvio, ou que explicasse a causa e efeito das coisas de forma lógica entra em jogo, com o objetivo de mostrar aquilo que é e está acima de tudo.

A última praga é a cartada final que YHWH usa para suplantar a dureza do coração faraônico. A narrativa é extrema e radical, lembrando a visão de Longino:

No meio da noite, Iahweh feriu todos os primogênitos na terra do Egito, desde o primogênito de Faraó, que deveria sentar-se em seu trono, até ao primogênito do cativo, que estava na prisão, e todo primogênito dos animais. Faraó levantou-se de noite, com todos os seus servos e todo o Egito; e houve um grande clamor no Egito, pois não havia casa onde não houve um morto. ${ }^{14}$

A narrativa não pormenoriza como aconteceu, mas não deixa dúvidas do tamanho da aflição vivida. Faraó cede, porque é equiparado a todos: servos, cativos e animais. O mal que lhe sucedeu, foi o mesmo mal que atingiu a todo e qualquer um e ele não teve o

\footnotetext{
${ }^{14}$ Bíblia de Jerusalém. Êxodo 12, 29-30
} 
controle sobre isto. YHWH mostrou seu braço forte e foi mais forte que o coração duro do Faraó.

Para marcar o evento, uma celebração foi instaurada. Mas, em contraste ao grande clamor de dor levantado, a festa seria íntima, discreta, dentro de casa A Páscoa não deixaria que aquele momento não se fizesse história.

O Capítulo anterior do êxodo, outra narrativa similar, prenuncia na fala de YHWH o que aconteceria, mostrando o contraste na recepção do evento:

\begin{abstract}
"Assim diz Iahweh: à meia-noite passarei pelo meio do Egito. E todo primogênito morrerá na terra do Egito, desde o primogênito de Faraó, que deveria sentar-se em seu trono, até o primogênito da escrava que está à mó, e até mesmo os primogênitos do gado. Haverá então na terra do Egito um grande clamor como nunca houve antes, nem haverá jamais. Mas entre os filhos de Israel, desde os homens até aos animais, não se ouvirá ganir um cão, para que saibais que Iahweh fez uma distinção entre o Egito e Israel." 15
\end{abstract}

Há um nítido contraste, nesta narrativa entre o Egito e Israel. YHWH mostra seu poder acima das divindades egípcias. No entanto, o povo não celebraria esta vitória com atos de alegria. Segundo o texto bíblico, enquanto o anjo da morte visitava as casas e agia seguindo a ordem divina, o povo estaria celebrando sua primeira Páscoa. A ideia não era festejar, no sentido de demonstrar alegria, mas de tornar memória o evento.

Faraó, por fim, cedeu. E o povo correu para sua liberdade.

Mas o bloco da narrativa não se encerra aqui.

No capítulo 14 de Exxodo, a celebração da vitória exigiu efeitos ainda mais grandiosos. Embora agora, movido pelo luto e pavor que acompanharam esta última praga, cujo potencial invadiu a corte, Faraó ainda assim repete o movimento que fez por ocasião das outras pragas.

Nove vezes, ele prometeu libertar o povo, mas sua fala soou como engodo. Ele demostrou seu desprezo para com YHWH que acreditava em sua palavra e fazia cessar a praga em ação. Para a décima praga, não havia o que reverter. O Mal já tinha sido consumado, pois os primogênitos jaziam mortos, inclusive o primogênito do Faraó. Quando já em liberdade, os hebreus se veem perseguidos pelos egípcios. Faraó mudara de ideia.

\footnotetext{
${ }^{15}$ Bíblia de Jerusalém. Êxodo 11, 4-7.
} 
Novamente duas narrativas se cotejam. No verso 17 do capítulo 13 do livro de Exxodo, há a informação de que Faraó teria deixado o povo ir, mas no verso 5 do capítulo 14, a informação é que os hebreus teriam fugido. Dois escritores diferentes se apresentam aqui. No capítulo 13, temos o Eloísta, já no 14, é o Javista que narra ${ }^{16}$.

E o escritor Javista é grandioso ao narrar no capítulo 14 o célebre episódio em que o mar se abre para a passagem dos hebreus e como ele devora o exército egípcio tornando o desfecho desta narrativa extremo.

O bloco da narrativa desfecha no Canto da vitória, no capítulo 15 do Exxodo, quando se canta a grandeza de YHWH, onde, por fim, se encerra esta apresentação. Embora a narrativa do Gênesis, este bloco inicial do Êxodo é, de fato, o texto que, oficialmente, traz a figura de YHWH para a história do povo hebreu.

Por fim, é importante mencionarmos que o texto aqui presente não esgota todas as possibilidades originadas nas cenas descritas. Apesar da figura do "Totalmente Outro" de Bart ter sido por nós explorada, estudos futuros poderão discutir, por exemplo, se a visão popular prototípica desse Deus "totalmente outro" encontra ressonância em textos como o do Êxodo. Parece-nos essa uma questão que brinca com os sentidos, provocando-nos a pensar se não haveria, no texto, uma disputa entre quem executa melhor esse papel prototípico; disputa essa, da qual YHWH parece não participar, marcando sua posição em ser outro: totalmente outro.

Referências bibliográficas:

BART, Karl. Carta aos Romanos. Segundo a Quinta Edição Alemã (impressão de 1967) $1^{a}$ Parte CAPÍTULOS DE I À VII São Paulo Copyright Fonte Editorial Comércio de Livros Religiosos Ltda 5a Edição - 2008, pag. 697.

BÍBLIA DE JERUSALÉM. Edições Paulinas: SP, 1985.

BURKE, Edmund. Uma investigação filosófica sobre a origem de nossas idéias do sublime e do belo. Campinas, SP : Papirus : Editora da Universidade de Campinas, 1993. FREUD, Sigmund. Obras Completas. Domínio Público. Lelivros.

GUIA CONHEÇA A HISTÓRIA : EGITO . 1. ed. - São Paulo: On Line, 2016. Il LONGINO. Do sublime. São Paulo: Martins Fontes, 1996.

\footnotetext{
${ }^{16} \mathrm{O}$ original dos textos apresenta claramente no trecho do capítulo 13 citado o nome ELOHIM para falar de Deus. No capítulo 14, o termo usado para Deus é YHWH.
} 